\title{
DUAL BAND DUAL POLARIZED ANTENNA WITH HIGH EFFICIENCY FOR BASE TRANSCEIVER STATIONS
}

\author{
F. Hojjat Kashani \\ Iran University of Science and Technology \\ Iran
}

\author{
M. Shahpari \\ Iran University of Science and Technology \\ Ameri-Tech Company \\ Iran
}

\section{H. Ameri}

IT\&MMWAVES Company

Malaysia

\begin{abstract}
In this paper new array element for use in dual band dual polarized antenna will be introduced that has high efficiency (more than 95\%) and has high isolation in both $900 \mathrm{MHz}$ and $1800 \mathrm{MHz}$ bands. Also radiation pattern of this antenna is according to IEC recommendation.
\end{abstract}

\section{INTRODUCTION}

Todays almost all operators use two or more frequency bands for their communication services and the most usual bands are $900 \mathrm{MHz}$ and $1800 \mathrm{MHz}$. In recent years considerable increasing effort on the design of dual band band and dual polarized antenna has been observed. Some designs for dual band and dual polarized antennas have been reported that can be used as array elements in the BTS antenna [1-3]. These designs are commonly patch antennas and use multilayer substrate to enhance bandwidth although antenna efficiency will reduces to $60 \%$. Also authors of references designed and tested their antenna elements with linear vertical and horizontal polarizations while $\pm 45^{\circ}$ polarizations are needed. 
International Engineering Consortium (IEC) has published a new standard [4] and according that we need four pattern measurements in each slant plane to understand radiation characteristics truly.

In this paper new array element with high efficiency (more than $95 \%$ ) will be introduced that is ideal to use in dual band dual polarized BTS antennas and according to IEC standard.

\section{PROPOSED ANTENNA STRUCTURE}

Proposed antenna element in this paper could be divided to two parts: One part for $900 \mathrm{MHz}$ frequency and the other for $1800 \mathrm{MHz}$ frequency and both parts are capable of dual polarized operation. Fig. 1 illustrates antenna structure. In fact array element in this paper is formed from classical elements. However dipole antennas are inseparable part from any antenna textbook but they still form foundations of the researches of the scientists so that could be found in recent papers [5-10]. Microstrip and patch antennas have been presented later than dipoles and there are many discussions and different analyses in antenna books but we observe them daily with their novel configurations and new performances in papers [11-20].

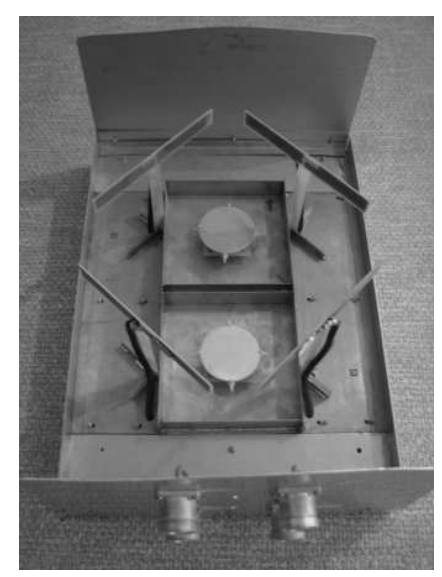

Figure 1. Proposed antenna structure.

\subsection{Dual Polarized Antenna for $900 \mathrm{MHz}$}

Radiation part of antenna in $900 \mathrm{MHz}$ band consists of four printed dipoles on the FR-4 substrate that are positioned on the rectangle arms. Dipoles on the same polarization direction are excited in phase. 
So we can write from array theory [21]:

$$
A F=e^{j k \sin \theta\left(-d_{x} \cos \phi+d_{y} \sin \phi\right)}+e^{j k \sin \theta\left(d_{x} \cos \phi-d_{y} \sin \phi\right)}
$$

Also for each slant dipole in $\phi= \pm 45^{\circ}$ can be written [22]:

$$
E=\frac{\cos \left(\frac{\pi}{2} \cos (\phi+\pi / 4) \sin \theta\right)}{\sqrt{1-\cos ^{2}(\phi+\pi / 4) \sin ^{2} \theta}} \sin \left(\frac{2 \pi}{\lambda} h \cos \theta\right)
$$

So antenna radiation pattern can be computed by multiplication of element factor and array factor. Presence of radiation part of $1800 \mathrm{MHz}$ between dipoles has not been considered in above equations but that's necessary to be considered in exact simulations.

Dipoles have $0.4 \lambda$ length and are positioned $0.381 \lambda$ above the ground plane. As Fig. 2 illustrates each dipole has an additional part to fix it above the ground plane. Additional printed track and coaxial cable play the role of Balun.

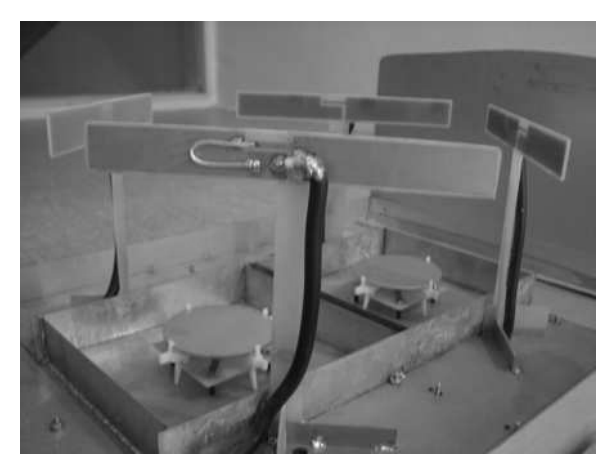

Figure 2. Dual polarized patch and dipoles structure.

\subsection{Dual Polarized Antenna for $1800 \mathrm{MHz}$}

L-shaped probe fed circular patch has been designed reradiate in $1800 \mathrm{MHz}$ frequency. Obviously thick substrate with low $\varepsilon_{r}$ is used to increase bandwidth and conducting walls reduce surface waves.

Field components can be written in regions I and II using Mode Matching Technique. For region I (under patch) we can write [23]:

$$
E_{z}=\sum_{n=0}^{\infty} J_{n}(k \rho) A_{n} \cos n \phi
$$




$$
\begin{aligned}
& H_{\rho}=\frac{1}{j \omega \mu_{0} \rho} \sum_{n=0}^{\infty} n J_{n}(k \rho) A_{n} \sin n \phi \\
& H_{\phi}=\frac{k}{j \omega \mu_{0}} \sum_{n=0}^{\infty} J_{n}^{\prime}(k \rho) A_{n} \cos n \phi
\end{aligned}
$$

Also for region II (between patch and conducting walls) we have:

$$
\begin{aligned}
E_{z} & =\sum_{n=0}^{\infty}\left[B_{n} J_{n}(k \rho)+C_{n} Y_{n}(k \rho)\right]\left[D_{n} \cos n \phi+E_{n} \sin n \phi\right] \\
H_{\rho} & =\frac{1}{j \omega \mu_{0} \rho} \sum_{n=0}^{\infty} n\left[B_{n} J_{n}(k \rho)+C_{n} Y_{n}(k \rho)\right]\left[D_{n} \sin n \phi-E_{n} \cos n \phi\right] \\
H_{\phi} & =\frac{k}{j \omega \mu_{0}} \sum_{n=0}^{\infty}\left[B_{n} J_{n}^{\prime}(k \rho)+C_{n} Y_{n}^{\prime}(k \rho)\right]\left[D_{n} \cos n \phi+E_{n} \sin n \phi\right]
\end{aligned}
$$

Because of boundary conditions in fields in region II $E_{z}$ equals to zero in the walls and fields outside of the patch reduce considerably and patch efficiency increased up to $95 \%$ as a result.

Circular patch has $0.36 \lambda$ radius and height. L-shaped probe consists of printed part and rods. Microstrip feeding network is under the ground plane and excites two L-shaped probes with $180^{\circ}$ phase difference. Impedance seen from each probe is $50 \Omega$ and simply a 1 to 2 divider with $0.5 \lambda$ length difference has been used to excite equal amplitude and out of phase each of dual arms. Electrical walls in addition to efficiency enhancement have effects on the radiation pattern so that fine tuning of half power beamwidth in horizontal plane has been done by tuning of length of wall.

\section{TEST AND MEASUREMENT TECHNIQUE}

According to IEC recommendation we need four pattern measurements to understand slant antenna performance appropriately. Polarizations of $+45^{\circ}$ reference antenna and $+45^{\circ}$ antenna under test do not remain actually same at entire antenna rotation and at $\phi=180^{\circ}$ antennas are cross polarized while they were co-polarized at $\phi=0^{\circ}$. So when antenna under test has been positioned in $+45^{\circ}$ related to horizon; reference antenna should be positioned in the following four directions +45 degree (co-polarized pattern measurement), -45 degree (cross polarized pattern measurement), horizontal direction and vertical direction. Although this measurement technique does not satisfy copolar and cross-polar definitions correctly but often is called in this way. 


\section{TEST AND MEASUREMENT RESULTS}

This section presents results of test and measurement of proposed antenna. Since antenna has four ports results are presented separately to prevent confusion of reader. Also because antenna is symmetrical about $\pm 45^{\circ}$ polarizations just $+45^{\circ}$ polarization results will be presented.

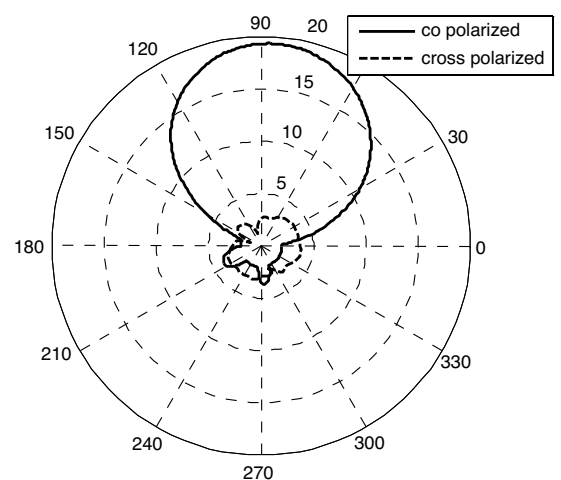

Figure 3. Co \& cross polarized patterns at $900 \mathrm{MHz}$.

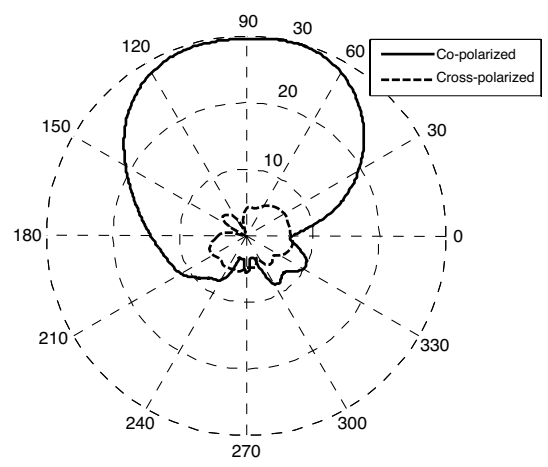

Figure 5. Co \& cross polarized patterns at $1800 \mathrm{MHz}$.

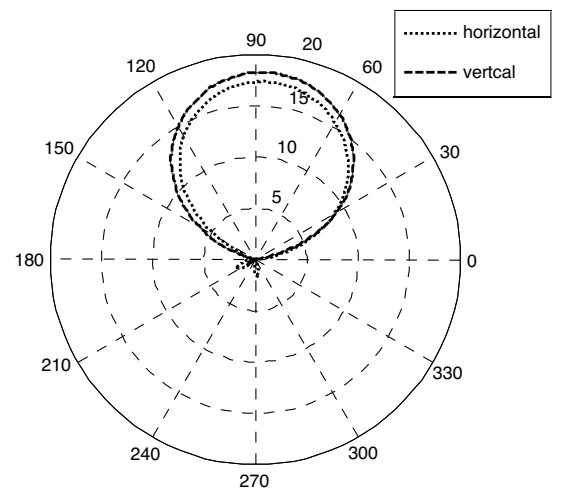

Figure 4. Patterns at $900 \mathrm{MHz}$ with transmitter in horizontal and vertical directions.

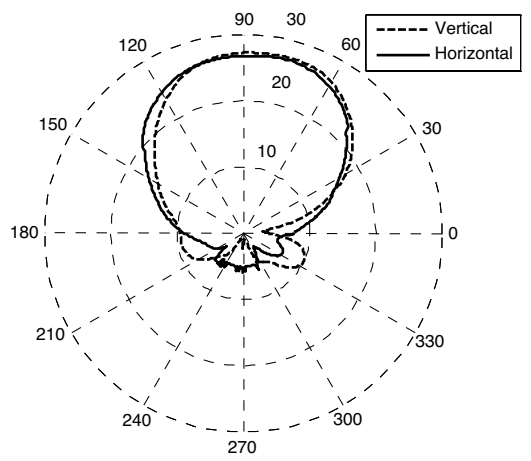

Figure 6. Patterns at $1800 \mathrm{MHz}$ with transmitter in horizontal and vertical directions.

Figure 3 illustrates co-polarized and cross polarized patterns for $+45^{\circ}$ polarization with $900 \mathrm{MHz}$ frequency. Acceptable and 
1376

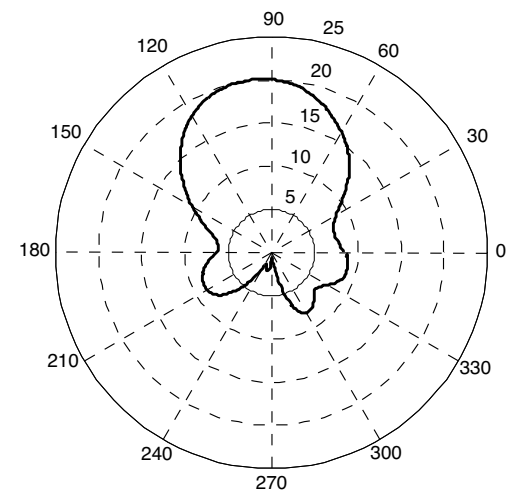

Figure 7. Measured pattern in $y-z$ plane and $900 \mathrm{MHz}$.
Hojjat Kashani, Shahpari, and Ameri

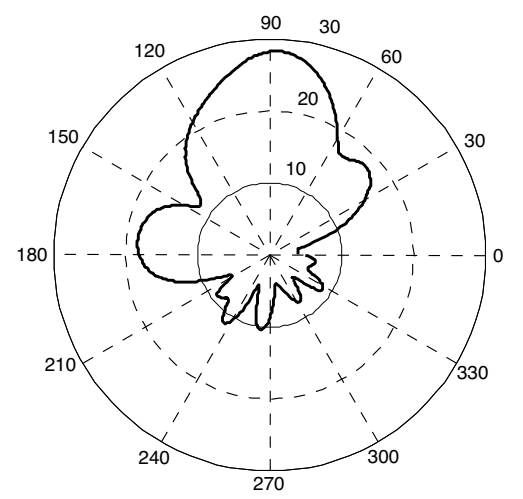

Figure 8. Measured pattern in $y-z$ plane and $1800 \mathrm{MHz}$.

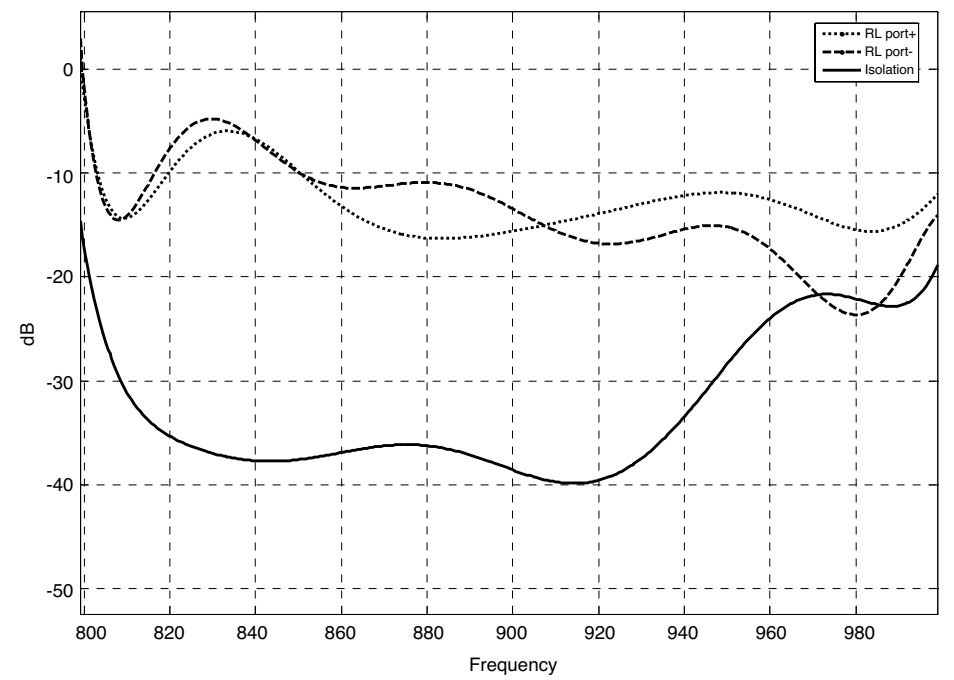

Figure 9. Measured RL and isolation between positive and negative ports at $900 \mathrm{MHz}$.

suitable cross polarization level can be noted. Fig. 4 shows pattern measurement when transmitter is in horizontal and vertical directions. As seen in Fig. 4, difference of horizontal and vertical levels is less than $0.75 \mathrm{~dB}$ in all directions. Similarly Fig. 5 and Fig. 6 illustrate measured co-polarized, cross polarized patterns and reference antenna in all horizontal and vertical directions in $1800 \mathrm{MHz}$ frequency. As seen in Fig. 6 difference of horizontal and vertical polarization levels is less 


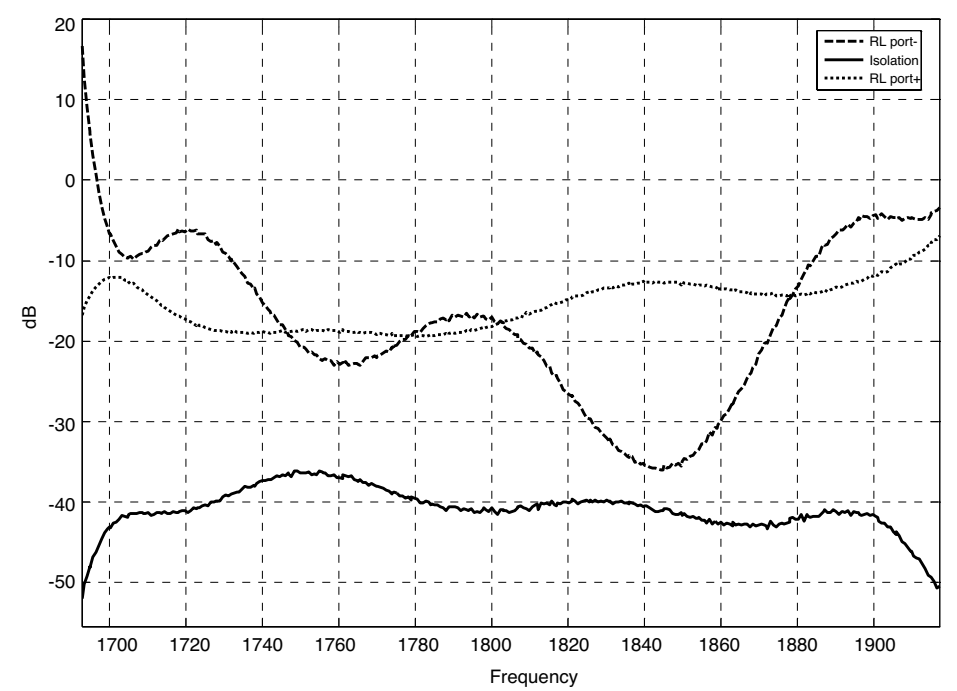

Figure 10. Measured RL and isolation between positive and negative ports at $1800 \mathrm{MHz}$.

than $3 \mathrm{~dB}$ in all directions and is exactly according to IEC standard.

Linear arrays on vertical axes are used achieve higher gain and narrow beamwidth. Fig. 7 and Fig. 8 illustrate measured patterns of antenna in vertical plane in $900 \mathrm{MHz}$ and $1800 \mathrm{MHz}$ frequencies.

Measured results of return loss and isolation for $\pm 45^{\circ}$ ports are presented in Fig. 9 for $900 \mathrm{MHz}$ band and in Fig. 10 for $1800 \mathrm{MHz}$ band. As results show all four ports are well matched and have a good isolation from each other.

\section{CONCLUSION}

New dual band dual polarized antenna element has been proposed that has appropriate performance in $900 \mathrm{MHz}$ and $1800 \mathrm{MHz}$ band and is low cost, easy to manufacture, suitable for mass production. Proposed antenna in addition to high efficiency (more than 95\%) has a desirable isolation characteristic and its radiation pattern is according to IEC standard.

\section{ACKNOWLEDGMENT}

The authors are grateful to Iran Telecommunication Research Center (ITRC) for its financial support for this project. The authors would 
also like to express their sincere gratitude to Mr. Saeed Parsania for and Mr. Morteza Nazari for fabrication of antenna and Mr. Aboutorab for his efforts on antenna test.

\section{REFERENCES}

1. Chiou, T.-W. and K.-L. Wong, "A compact dual-band dualpolarized patch antenna for $900 / 1800 \mathrm{MHz}$ cellular systems," IEEE Trans. Antennas and Propagation, Vol. 51, No. 8, 19361940, 2003.

2. Chiou, T.-W. and K.-L. Wong, "A compact dual-polarized aperture coupled patch antenna for GSM900/1800 MHz systems," IEEE Procon APMC, 95-98, 2001.

3. Lindmark, B., "A dual polarized dual band microstrip antenna for wireless communications," Proc. IEEE. Conf. on Aerospace, 333-338, 1998.

4. www.iec.org

5. Poljak, D. and V. Doric, "Wire antenna model for transient analysis of simple grounding systems, Part I: The vertical grounding electrode," Progress In Electromagnetics Research, PIER 64, 149-166, 2006.

6. Poljak, D. and V. Doric, "Wire antenna model for transient analysis of simple grounding systems, Part II: The horizontal grounding electrode," Progress In Electromagnetics Research, PIER 64, 167-189, 2006.

7. Li, J.-Y. and Y.-B. Gan, "Multi-band characteristic of open sleeve antenna," Progress In Electromagnetics Research, PIER 58, 135$148,2006$.

8. Eldek, A. A., "Design of double dipole antenna with enhanced usable bandwidth for wideband phased array applications," Progress In Electromagnetics Research, PIER 59, 1-15, 2006.

9. He, Q.-Q. and B.-Z. Wang, "Radiation patterns synthesis for a conformal dipole antenna array," Progress In Electromagnetics Research, PIER 76, 327-340, 2007.

10. Wu, Y.-J., B.-H. Sun, J.-F. Li, and Q.-Z. Liu, "Triple band omni-directional antenna for WLAN application," Progress In Electromagnetics Research, PIER 76, 477-484, 2007.

11. Kaya, A., "Meandered slot and slit loaded compact microstrip antenna with integrated impedance tuning network," Progress In Electromagnetics Research B, Vol. 1, 219-235, 2008. 
12. Min, K.-S., M.-S. Kim, C.-K. Park, and M. D. Vu, "Design for PCS antenna based on wibro-mimo," Progress In Electromagnetics Research B, Vol. 1, 77-83, 2008.

13. Abbaspour, M. and H. R. Hassani, "Wideband star shaped microstrip patch antenna," Progress In Electromagnetics Research $B$, Vol. 1, 61-68, 2008.

14. Sharma, A. and G. Singh, "Design of single pin shorted three dielectric loaded substrates rectangular patch microstrip antenna for communication systems," Progress In Electromagnetics Research B, Vol. 1, 157-165, 2008.

15. Su, D. Y., D. M. Fu, and D. Yu, "Genetic algorithms and method of moments for the design of PIFAs," Progress In Electromagnetics Research Letters, Vol. 1, 9-18, 2008.

16. Abdelaziz, A. A., "Bandwidth enhansment of microstrip antenna," Progress In Electromagnetics Research, PIER 63, 311317, 2006.

17. Gao, S. and A. Sambell, "A simple broadband printed antenna," Progress In Electromagnetics Research, PIER 60, 119-130, 2006.

18. Mavridis, A. A., G. A. Kyriacou, and J. N. Sahalos, "On the design of patch antennas tuned by transversely magnetized lossy ferrite including a novel resonating mode," Progress In Electromagnetics Research, PIER 62, 165-192, 2006.

19. Wang, F. J. and J.-S. Zhang, "Wideband cavity-backed patch antenna for pcs/imt $2000 / 2.4 \mathrm{GHz}$ wlan," Progress In Electromagnetics Research, PIER 74, 39-46, 2007.

20. Ang, B.-K. and B.-K. Chung, "A wideband E-shaped microstrip patch antenna for 5-6 GHz wireless communications," Progress In Electromagnetics Research, PIER 75, 397-407, 2007.

21. Elliott, R. S., Antenna Theory and Design, Prentic-Hall, 1981.

22. Kraus, J. D., Antennas: for all Applications, 3rd edition, McGraw-Hill, 2002.

23. Garg, R., P. Bhartia, I. Bhal, and A. Ittipiboon, Microstrip Antenna handbook, Artech House, 2001. 